\title{
Design, Construction and Calibration of Automatic Street Light Controller Using Light Dependent Resistor (LDR)
}

\author{
*ECHEWEOZO, EO; OKORO, NO; NGELE, P
}

\author{
Department of Physics with Electronics, Evangel University Akaeze, Ebonyi State, Nigeria. \\ *Corresponding Author Email: eugeneozo@evangeluniversity.edu.ng
}

\begin{abstract}
Automatic street light power saving system using the Light Dependent Resistor (LDR) is a simple and powerful concept, to switch ON/OFF the street light system automatically. It automatically switches ON the streetlight when the sunlight goes below the visible region of our eyes and switches OFF the streetlight when ample amount of sunlight is available. From this work, it was observed that the implementation of LDR in streetlight circuit design would reduce the running cost of street lightning system by $51.7 \%$.
\end{abstract}

\section{DOI:https://dx.doi.org/10.4314/jasem.v23i3.14}

Copyright: Copyright (C) 2019 Echeweozo et al. This is an open access article distributed under the Creative Commons Attribution License (CCL), which permits unrestricted use, distribution, and reproduction in any medium, provided the original work is properly cited.

Dates: Received: 17 February 2019; Revised: 21 March 2019; Accepted 22 March 2019

Keywords: Streetlight, Energy, Light, Dependent, Resistor.

Street lighting provides a safe night time environment for all road users including pedestrians. Research indicates that night-time vehicular accidents are significantly reduced by the provision of street lighting, (Komal et al, 2017). It also helps to reduce the fear of crime, and encourages social inclusion by providing an environment in which people feel they can walk in hours of darkness. Providing street lighting is one of the most important and expensive responsibilities in any city. Lighting can account for $10-38 \%$ of the total energy bill in typical cities worldwide, (Ahmed et al, 2013). Inefficient lighting wastes significant financial resources each year, (Popa and Cepisca, 2011).

Energy efficient technologies and design can drastically cut street lighting costs. The current trend is the introduction of automated solutions to control street lighting, (Mohelnikova, 2008).Automation is intended to reduce man power with the help of intelligent systems. Power saving is important as the sources of the electric power are diminishing due to various reasons. The main aim of this paper is to explain a cost effective way of running street light by designing an Automatic street light power saving system using the Light Dependent Resistor (LDR).

LDR (Light Dependent Resistor) is a device whose sensitivity depends upon the intensity of light falling on it. When the strength of the light falling on LDR increases the LDR resistance decreases, if the strength of the light falling on LDR is decreased, resistance increases. When there is no light, the resistance of LDR is in the range of mega ohms, while in the presence of light or in brightness it decreases by few hundred ohms. LDRs have a sensitivity that varies with the wavelength of the light applied.

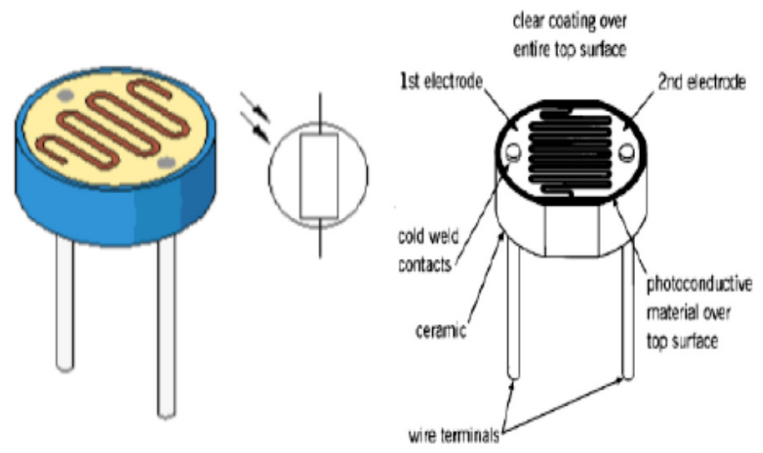

Fig 1: showing light dependent resistor

A Light Dependent Resistor works on the principle of photo conductivity. Photo conductivity is an optical phenomenon in which the materials conductivity is increased when light is absorbed by the material. When light shines i.e. when the photons fall on the device, the electrons in the valence band of the semiconductor material are excited to the conduction band. These photons in the incident light should have energy greater than the band gap of the semiconductor material to make the electrons jump from the valence band to the conduction band. Hence when light having enough energy strikes on the device, more and more electrons are excited to the conduction band which results in large number of charge carriers. The result 
of this process is more and more current starts flowing through the device when the circuit is closed and hence it is said that the resistance of the device has been decreased.

\section{MATERIALS AND METHOD}

The following materials were employed for the design. They are:

Table 1: Showing the list of components and quantity used in the design.

\begin{tabular}{cll}
\hline S/N & Component & Quantity \\
\hline 1 & Transistor BC 547 & 2 \\
2 & Light dependent resistor & 1 \\
3 & Relay (12V) & 1 \\
4 & Resistor 1K & 1 \\
5 & 100k potentiometer & 1 \\
6 & Power supply 12V & 1 \\
7 & Connecting wire & \\
8 & Bread board & \\
9 & In4007 diode & 1 \\
10 & AC supply & \\
11 & AC load (bulb) & 1 \\
\hline
\end{tabular}

Before mounting any component in the circuit it is a good practice to check whether a component works properly or not so that time consumption in troubleshooting can be avoided. For testing LDR the range of multi meter was set on resistance measurement. After that the lids were placed on the legs of LDR (as LDR have no polarity so you can connect any lid with leg). Measure the resistance of LDR in the light or brightness, resistance must be low. Now cover LDR properly so that no light beam fall in it, again measure the resistance it must be high. If you got the same result it means that LDR is good.

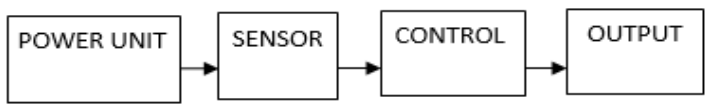

Fig 2: showing the block diagram of the design

Power Unit: The power unit is made up of: $12 \mathrm{~V}$ battery/ power supply

Sensor: Light dependent resistor

Control Unit: This unit includes:

100k potentiometer, 547 transistor, Diode and12V Relay.

Output: The output is made up of The AC bulb

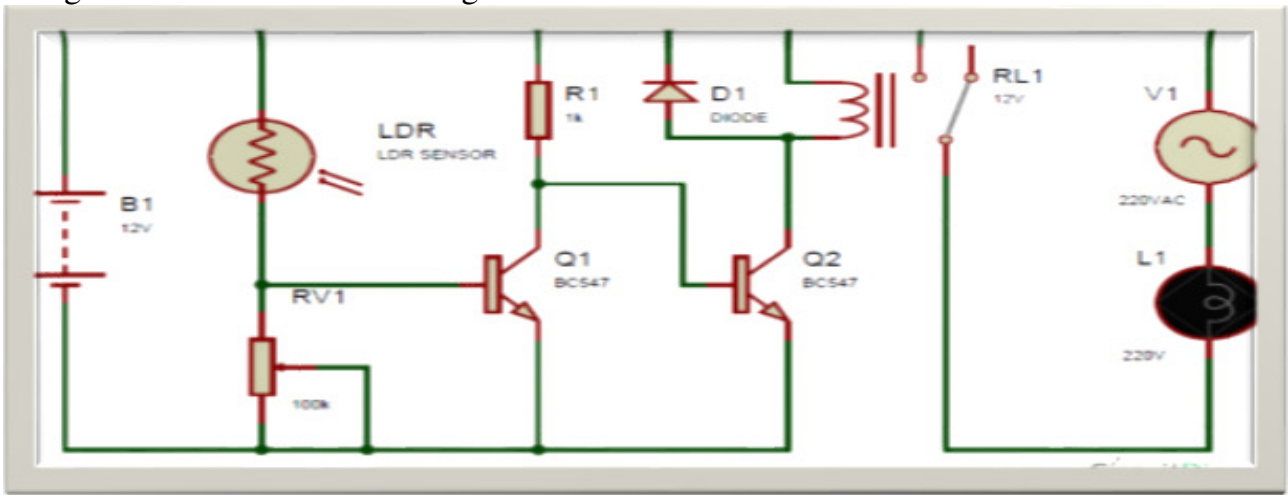

Fig 3: showing the circuit diagram of the design

Whenever light falls over LDR its resistance get decreased and transistor Q1 turns ON while the collector current of this transistor goes LOW, and this makes the second transistor turns OFF due to getting a LOW signal at its base, hence the transistor will be in cut-off region thus the relay will not be energized, therefore the AC load remains in the OFF state. Now whenever LDR senses Darkness, transistor Q1 is turned $\mathrm{ON}$ due to increase in the resistance of LDR which is responsible for voltage drop at the base of Q1. Due to a LOW signal at the Q1 base, Q2 transistor gets a HIGH signal from the collector of Q1 and energizes the Relay which turns $\mathrm{ON}$ the AC load that is connected to it. A $100 \mathrm{~K}$ potentiometer is also used for setting up the sensitivity of the circuit and diode D1 is used for decaying the energy stored in the relay coil when the circuit is switched off.

In order to calculate the electrical energy used and saved in this work the formula below would be used

$$
\text { Energy }(\text { electrical })=\operatorname{power}(P) \times \operatorname{Time}(T)
$$

Where $\mathrm{E}$ is in kilowatt-hours (KWh); $\mathrm{P}$ is in Watts and $\mathrm{T}$ is in Hours

\section{RESULT AND DISCUSSION}

The design was tested for a week to determine the time it comes ON (when it is dark) and the time it goes OFF (when it senses light). 
Table 2: showing the ON and OFF time of the design for a week

\begin{tabular}{llll}
\hline $\begin{array}{l}\text { Days of } \\
\text { week }\end{array}$ & Time it came ON & Time it went OFF \\
\hline Sunday & $7.00 \mathrm{pm}$ & $6.33 \mathrm{am}$ & \\
Monday & $6.58 \mathrm{pm}$ & $6.30 \mathrm{am}$ & \\
Tuesday & $7.00 \mathrm{pm}$ & $6.35 \mathrm{am}$ & \\
Wednesday & $7.01 \mathrm{pm}$ & $6.33 \mathrm{am}$ & \\
Thursday & $7.00 \mathrm{pm}$ & $6.34 \mathrm{am}$ & \\
Friday & $7.01 \mathrm{pm}$ & $6.35 \mathrm{am}$ & \\
Saturday & $7.00 \mathrm{pm}$ & $6.35 \mathrm{pm}$ & \\
& Average time ON & Average & time \\
& $=7.00 \mathrm{pm}$ & OFF=6.34am & \\
\hline
\end{tabular}

The table above shows that the controller was $\mathrm{ON}$ for $11 \mathrm{hrs}$, 34mins per day (7.00pm-6.34am).11hrs $34 \mathrm{mins}=11.567 \mathrm{hrs}$.

Using the equation above, the total electrical energy consumed with the use of the controller per day is $0.174 \mathrm{KWh}$.Total electrical energy consumption per day (24hrs) without the use of the controller is $0.360 \mathrm{KWh}$, so the electrical energy was saved per day by using the automatic light controller is $0.186 \mathrm{KWh}$.

Electrical Energy saved in $\%=\frac{\text { Total energy saved par day }}{\text { total energy consumed per day }}$

This shows the design saved $51.7 \%$ of Electrical Energy. With $15 \mathrm{~W}=0.015 \mathrm{KW}$ energy saving bulb the total, electrical energy consumed was calculated as Considering multiple higher wattage street lightning points, implementing this design will reduce cost of running the street light by $51.7 \%$. This will help to save money which could be used for other basic infrastructure.
Conclusion: Automatic controlled street light using LDR helps to save a large amount of electric power which is wasted in conventional street lighting system. Based on the design result, it is clear that the design and construction of the automatic street light controller was successful, readings were taken to ascertain its functionality and it was deduced that the implementation of this design would reduce the running cost of street lightning system by $51.7 \%$.

\section{REFERENCES}

Ahmed, SA; Anupriya, AC; Shalini, D and Shweta, V (2013). Solar Powered Led Streetlight with Automatic Intensity Control. International Journal of Innovative Research in Electrical, Electronics, Instrumentation and Control Engineering.3 (6), pp 32-36

Komal, J; Apeksha, M; Shrraddha, R; Payal, S; Arya, C S (2017). Automatic Street light Control System: Imperial Journal of Interdisciplinary Research (IJIR) 3, pp1362-2454.

Mohelnikova, J (2008). Electric Energy Savings and Light Guides, Energy \&Environment: $3^{\text {rd }}$ IASME/WSEAS International Conference on, Cambridge, UK, pp.470-474

Popa,M; Cepişcă,C (2011). Energy Consumption Saving Solutions Based on Intelligent Street Lighting Control System: U.P.B. Sci. Bull., Vol. 73, pp. 297-308. 